\title{
Comment on: prospective study of stereotactic body radiation therapy for hepatocellular carcinoma on waitlist for liver transplant
}

\author{
Nicolas Tabchouri ${ }^{1}$, Petru Bucur ${ }^{1}$, Ephrem Salamé $^{1,2,3}$ \\ ${ }^{1}$ Department of Digestive Surgery, Hepatobiliary Surgery and Liver Transplantation, University Hospital of Tours, CHU Tours, Tours, France; \\ ${ }^{2}$ INSERM U1082, Poitiers, France; ${ }^{3}$ FHU SUPORT, Tours, France \\ Correspondence to: Nicolas Tabchouri. Department of Digestive Surgery, Hepatobiliary Surgery and Liver Transplantation, University Hospital of \\ Tours, CHU Tours, F37042, Tours, France. Email: nicolastabchouri@gmail.com. \\ Comment on: Wong TC, Lee VH, Law AL, et al. Prospective study of stereotactic body radiation therapy for hepatocellular carcinoma on waitlist for \\ liver transplant. Hepatology 2021. [Epub ahead of print]. doi:10.1002/hep.31992.
}

Submitted Jul 14, 2021. Accepted for publication Jul 25, 2021.

doi: 10.21037/hbsn-21-287

View this article at: https://dx.doi.org/10.21037/hbsn-21-287

We read with great interest the recently published article of Wong et al. (1). Through their study, the authors sought to evaluate the efficacy and safety of stereotactic body radiation therapy (SBRT) in patients presenting with hepatocellular carcinoma (HCC), awaiting liver transplantation (LT). This is the first prospective study to analyze SBRT as a bridging treatment before LT and compare it to other bridging therapies such as transarterial chemoembolization (TACE) and high intensity focused ultrasound (HIFU).

Regarding SBRT as a bridging treatment, current literature is scarce, with only a few retrospective studies published, with small sample sizes (up to 38 patients undergoing SBRT and then LT) (2,3). SBRT has been more investigated as an HCC treatment modality outside of LT setting and very promising results were found especially in terms of local control (4). These encouraging results led to SBRT being included by most LT teams worldwide in their bridging therapy arsenal. Nonetheless more robust data is needed to confirm SBRT efficacy and safety, which underlines the importance of this study.

We believe several points in this paper are open for discussion and further analysis. Although SBRT patients were included prospectively from 2015 to 2020, the control groups (TACE and HIFU) were reviewed retrospectively and included patients treated since 2010. The authors argue that the resulting bias has minimal implications due to the fact that over the study period there was no change in HCC selection, Model for End-Stage Liver Disease (MELD) exception system, tumor response evaluation and organ availability. However, TACE techniques have evolved and efficacy of selective/super-selective TACE has increased during the last decade $(5,6)$. Although TACE is usually preferred when there are multiple tumors and SBRT/ HIFU/radiofrequency ablation (RFA) in case of Child-Pugh $\mathrm{B}$ and single tumor, number and size of tumors were not significantly different between TACE and SBRT groups and more than $50 \%$ of SBRT patients were Child-Pugh A. As a result, most of the SBRT group patients could have been candidates for TACE and thus applying a randomized controlled trial could have been more adapted. Selection bias should be taken into consideration when interpreting the final results.

Regarding TACE procedure, it was performed nonselectively (conventional right or left liver TACE) and not superselectively as stated (no single segment or noduleselective TACE). Local TACE technique could maybe explain why 1-year local tumor control is so low in TACE group $(43.5 \%)$ compared with results reported from other published series (around 75-80\%) (5,6). Furthermore, among TACE patients, $60 \%$ were Child-Pugh A, $56 \%$ had 1 tumor, and a median size of $2.2 \mathrm{~cm}(0.8-6.3 \mathrm{~cm})$. These patients could have been candidates for other ablative techniques like RFA in most centers.

In this study, the authors report significantly better 1-year tumor control rate in SBRT patients awaiting LT, compared with TACE/HIFU patients $(92.3 \%$ vs. $43.5 \%$ vs. $33.3 \%$ respectively, $\mathrm{P}=0.02)$ and lower 2 -year dropout rates $(20 \%$ SBRT vs. 35\% TACE vs. $41 \%$ HIFU) even though lesion 
size and MELD score were higher in the SBRT group compared with the TACE group. Although sample size is small (40 SBRT and 110 TACE/HIFU patients, of which 27 and 60 ultimately underwent LT, respectively), groups were relatively homogeneous in terms of tumor burden [similar number of lesions and alpha-foetoprotein (AFP) levels]. The fact that SBRT group yielded the best results in terms of local control despite bigger lesions (compared with the TACE group) emphasizes its efficacy. Upon LT, there were no differences between the 3 groups in terms of tumor stage, the number and size of lesions or AFP levels while MELD score was still higher in the SBRT group compared with the TACE group. Tumor necrosis and complete pathological response rates were highest in SBRT group compared to TACE/HIFU groups, with further reinforces its efficacy. Furthermore, 4 patients in SBRT group never underwent LT because they were considered treated, and in those undergoing LT, median waiting time was twice as long as TACE/HIFU patients. It could be hypothesized that this is due to longer local tumor control with SBRT.

Another major point to mention is the lack of comparison between SBRT and RFA or radioembolisation (RE). The authors only compared SBRT with TACE and HIFU and even though this is due to local practice, external validity of these results is low. Indeed, many transplantation centers throughout the world do not use HIFU as a bridging treatment before LT, and instead, use RFA and RE which are not evaluated in the current study.

In conclusion, this study yields important results that further reinforce SBRT as a bridging treatment for HCC before LT. This represents a first step in obtaining more robust data but there is still desperate need for randomized controlled trials in order to obtain solid conclusions.

\section{Acknowledgments}

Funding: None.

\section{Footnote}

Provenance and Peer Review: This article was commissioned by the editorial office of Hepatobiliary Surgery and Nutrition. The article did not undergo external peer review.

Conflicts of Interest: All authors have completed the ICMJE uniform disclosure form (available at https://hbsn. amegroups.com/article/view/10.21037/hbsn-21-287/coif). The authors have no conflicts of interest to declare.
Ethical Statement: The authors are accountable for all aspects of the work in ensuring that questions related to the accuracy or integrity of any part of the work are appropriately investigated and resolved.

Open Access Statement: This is an Open Access article distributed in accordance with the Creative Commons Attribution-NonCommercial-NoDerivs 4.0 International License (CC BY-NC-ND 4.0), which permits the noncommercial replication and distribution of the article with the strict proviso that no changes or edits are made and the original work is properly cited (including links to both the formal publication through the relevant DOI and the license). See: https://creativecommons.org/licenses/by-nc-nd/4.0/.

\section{References}

1. Wong TC, Lee VH, Law AL, et al. Prospective study of stereotactic body radiation therapy for hepatocellular carcinoma on waitlist for liver transplant. Hepatology 2021. [Epub ahead of print]. doi:10.1002/hep.31992.

2. Mannina EM, Cardenes HR, Lasley FD, et al. Role of Stereotactic Body Radiation Therapy Before Orthotopic Liver Transplantation: Retrospective Evaluation of Pathologic Response and Outcomes. Int J Radiat Oncol Biol Phys 2017;97:931-8.

3. Sapisochin G, Barry A, Doherty M, et al. Stereotactic body radiotherapy vs. TACE or RFA as a bridge to transplant in patients with hepatocellular carcinoma. An intention-totreat analysis. J Hepatol 2017;67:92-9.

4. Bujold A, Massey CA, Kim JJ, et al. Sequential phase I and II trials of stereotactic body radiotherapy for locally advanced hepatocellular carcinoma. J Clin Oncol 2013;31:1631-9.

5. Bettinger D, Gkika E, Schultheiss M, et al. Comparison of local tumor control in patients with HCC treated with SBRT or TACE: a propensity score analysis. BMC Cancer 2018;18:807.

6. Chu HH, Gwon DI, Kim JH, et al. Drug-Eluting Microsphere Versus Cisplatin-Based Transarterial Chemoembolization for the Treatment of Hepatocellular Carcinoma: Propensity Score-Matched Analysis. AJR Am J Roentgenol 2020;215:745-52.

Cite this article as: Tabchouri N, Bucur P, Salamé E. Comment on: prospective study of stereotactic body radiation therapy for hepatocellular carcinoma on waitlist for liver transplant. HepatoBiliary Surg Nutr 2021;10(4):510-511. doi: $10.21037 / \mathrm{hbsn}-21-287$ 